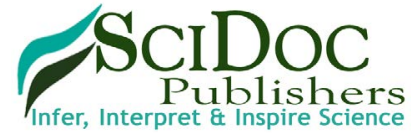

International Journal of Food Science, Nutrition and Dietetics (IJFS)

ISSN:2326-3350

\title{
Hyperhomocysteinemia and Type 2 Diabetes in Côte d'Ivoire
}

Research Article

Diagou JJ ${ }^{1,2,4}$, Ocho-Anin Atchibri AL ${ }^{1}$, Acka F $F^{4}$, Ake $\mathrm{M}^{3}, \mathrm{~N}^{\prime}$ Guessan-Blao R ${ }^{2}$, Zanon TG ${ }^{2}$, Kouassi D $\mathrm{D}^{2,3,4}$

${ }^{1}$ Laboratory of Nutrition and Food Safety, UFR of Sciences and Food Technologies, Nangui Abrogoua University, Côte d'Ivoire.

${ }^{2}$ Laboratory of Research and Medical Biology; National Institute of Public Health (INSP), Abidjan, Côte d'Ivoire.

${ }^{3}$ Nutrition Research Center, INSP.

${ }^{4}$ Antidiabetic Center of Abidjan (CADA), INSP.

\section{Abstract}

The hyperhomocysteinemia is associated with the development and the accentuation of the cardiovascular complications of the type 2 diabetes. The objective of this study was to evaluate the hyperhomocysteinemia in type 2 diabetic patients. This study was carried out in 200 volunteer type 2 diabetics, regularly monitored at the Antidiabetic Center of Abidjan (CADA). The non-diabetic control population was composed of 31 healthy presumptive volunteers. The homocysteine, the glycemia and the lipid parameters were measured by enzymatic methods on the biochemistry automaton Cobas c-311(Roche Diagnostics). The present study has revealed a prevalence of a moderate hyperhomocysteinemia of $36.50 \%$. The average hyperhomocysteinemia was of $14.84 \pm 3.26 \mu \mathrm{mol} / \mathrm{L}$. It was higher in men $(14.95 \pm 3.50 \mu \mathrm{mol} / \mathrm{L})$ than in women $(14.75 \pm$ $3.05 \mu \mathrm{mol} / \mathrm{L})$, with no significant difference, and was predominant in the Akan ethnic group $(57.53 \%)$. It evolved with age and was significantly increased between 50 and 70 years. The relative risk of the hyperhomocysteinemia was approximately $3\left(\mathrm{RR}=2.83 \approx 3\right.$, CI 95\%: 1.39-11.53, $\left.\mathrm{P}\left(\chi^{2}\right)<0.05\right)$. That suggests an association between the hyperhomocysteinemia and the type 2 diabetes. The observed $\chi^{2}$ is greater than $\chi^{2}(1 ; 0.95)$, giving to think that the hyperhomocysteinemia risk is significantly higher in diabetic hyperhomocyteinemic patients than in non-diabetic controls. Moreover, there was a significant difference of homocysteinemia between that of the hyperhomocysteinemic diabetics $(14.84 \pm 3.26 \mu \mathrm{mol} / \mathrm{L})$ and the control group $(10.74 \pm 2.38 \mu \mathrm{mol} / \mathrm{L})$. That suggests an increased involvement of the hyperhomocysteinemia in the development of the cardiovascular diseases in our diabetic patients. However, the lipid parameters are normalized in our hyperhomocysteinemic diabetic patients, due to the effect of the clinical and nutritional treatment. The hyperhomocysteinemia is a reality in Côte d'Ivoire. It should be the object of sensibilization and reinforcement of the dietary and therapeutic measures, in order to minimize the risk of the cardiovascular diseases incurred by the type 2 diabetics.

Keywords: Hyperhomocysteinemia; Cardiovascular Risk Factor; Type 2 Diabetes.

\section{Introduction}

The homocysteine is a non-proteinogenic sulfur-containing amino acid, intermediate in the metabolism of methionine [1]. It is synthesized by all cells of the body and catabolized along two metabolic pathways: the pathway of the transsulfuration and the pathway of the remethylation [2]. This amino acid is an important indicator in the risk assessment of the cardiovascular diseases [3]. The plasma homocysteine level in a healthy individual is arbitrarily defined between 5 and $15 \mu \mathrm{mol} / \mathrm{L}$ [2]. The hyperhomocysteinemia is an abnormal accumulation of the plasma homocysteine resulting from its bad metabolization [4]. Its causes are nutritional (vitamin B deficiencies), genetic, therapeutic, or even physiological $[2,5]$.

The hyperhomocysteinemia is an independent cardiovascular risk factor [5]. It is associated with the development and the accentuation of the cardiovascular complications of the type 2 diabetes [6]. Its deleterious effect is particularly potent in the diabetics than in non-diabetics, leading to the emergence of the micro and macrovascular atherotrombotic diseases [7] and to a $90 \%$ mortality rate over 5 years [2]. However, there has been little study on the diabetic hyperhomocysteinemia in sub-Saharan Africa $[6,8]$. In Côte d'Ivoire, very little work has been devoted on hyperhomocysteinemia $[9,10]$ and none has evaluated the type 2 diabetic

\footnotetext{
*Corresponding Author:

Diagou JJ,

Laboratory of Nutrition and Food Safety, UFR of Sciences and Food Technologies, Nangui Abrogoua University, Côte d'Ivoire.

E-mail: vitalis.saturne@yahoo.fr
}

Received: March 09, 2018

Accepted: May 29, 2018

Published: May 30, 2018

Citation: Diagou JJ, Ocho-Anin Atchibri AL, Acka F, Ake M, N'Guessan-Blao R, Zanon TG, et al., Hyperhomocysteinemia and Type 2 Diabetes in Côte d'Ivoire. Int J Food Sci Nutr Diet. 2018;7(4):387-393. doi: http://dx.doi.org/10.19070/2326-3350-1800069

Copyright: Diagou JJ ${ }^{\circ}$ 2018. This is an open-access article distributed under the terms of the Creative Commons Attribution License, which permits unrestricted use, distribution and reproduction in any medium, provided the original author and source are credited. 
hyperhomocysteinemia. The hyperhomocysteinemia is practically or totally ignored in the treatment of diabetics in Côte d'Ivoire.

The present work consisted in the evaluating of the hyperhomocysteinemia in the type 2 diabetic patients in Côte d'Ivoire. Specifically, it was to determine its prevalence, describe its evolution according to the sex, the age and the ethnic group. To determine whether its relative risk is reduced or significantly increased. Then, assess whether there is a significant difference between the homocysteinemia, the glycemia and the lipid parameters in the hyperhomocysteinemic diabetics compared to the control group. This, in order to appreciate the necessity of the nutritional and clinical management of the diabetic hyperhomocysteinemia in Côte d'Ivoire.

\section{Methods}

\section{Type of Study}

This was a descriptive and cross-sectional study.

\section{Study population}

This study was conducted from September to December 2016, and has involved 231 subjects. The type 2 diabetic population was composed of 200 subjects, including 122 women and 78 men, aged from 23 to 86 years. They were recruited consecutively and randomly, among the type 2 diabetics regularly monitored at the Antidiabetic Center of Abidjan (CADA). The diabetic subjects included different Ivorian and foreign ethnic groups, composed of 171 nationals and 29 non-nationals. The non-diabetic control population consisted of 31 healthy volunteers, including 18 men and 13 women, aged from 22 to 50 years. They were recruited from the health staff of the National Institute of Public Health (INSP) of Abidjan-Côte d'Ivoire and among other people outside the institute. The study protocol has been approved by the Pasteur Institute of Côte d'Ivoire. All the subjects were informed of the purpose of the study and have given their informed consent of participation.

\section{Blood sampling and determination of biochemical param- eters}

The venous blood sampling of the fasting subjects (12 hours) was performed, in a semi-sitting position, in the sampling room of the INSP Medical Research and Biology Laboratory. The blood was collected in $5 \mathrm{ml}$ Vacutainer tubes, immediately placed in a cooler between the collection and the centrifugation. The EDTA (Ethylene diamine tetra acetic acid) tubes (purple), for the determination of the homocysteine; the $\mathrm{NaF}$ (sodium fluoride) tubes (gray), for the determination of the glycemia; and the dry tubes (red) for the lipid assay. After the centrifugation of the tubes at $3000 \mathrm{rpm}$ for 10 minutes, the plasmas were aliquoted and stored at $-20^{\circ}$ C. At the time of the assays, the plasma samples were thawed at the room temperature and homogenized. The homocysteine, the glycemia and the lipid parameters were measured by enzymatic methods on the biochemistry automaton Cobas c-311(Roche Diagnostics), using the Cobas-Integra kits (Germany).

The homocysteine, by the enzymatic cycling method. The glycemia, by the glucose oxidase method (GOD-PAP). The triglycer- ides, by the glycerol-phosphate oxidase method (GOP-PAP). The total cholesterol, by the cholesterol oxidase method (CHODPAP). The HDLs were evaluated by the enzymatic colorimetric method (Direct Homogeneous Test for HDL-Cholesterol). The LDLs were determined by the formula of Fredwald et al., [27]. The biochemical reference values of the glycemia and the lipids are those of the Ivorian adult presumed healthy, in force at the INSP-Abidjan and coming from the study of Yapo et al., [8].

\section{Statistical Analyses}

The data were recorded and processed by the Excel 2013 application. The variables such as the age, the duration of diabetes, the body mass index, the homocysteinemia, the glycemia, the total cholesterol, the triglycerides, the cholesterols LDL and HDL, were expressed under the form of mean \pm standard deviation. These quantitative variables were evaluated via the Fisher test for the equality of the variances, and the Student's test for the comparison of the averages. The relationship between the hyperhomocysteinemia and the type 2 diabetes and the estimation of the relative risk of the hyperhomocysteinemia were assessed by the Pearson's chi-square $\left(\chi^{2}\right)$ test. The confidence interval (CI 95\%) of the relative risk (RR) was evaluated by the Mittinen method. For these tests, the significance was allowed for $\mathrm{p}<0.05$.

\section{Results}

\section{General presentation of the diabetic and the control popula- tion}

The type 2 diabetic population and the control group presented the sociodemographic characteristics of the Table 1. The sex ratio of the diabetics was of 0.6 . The average age was $55 \pm 10.78$ years. The duration of the diabetes was $8.5 \pm 0.70$ years. A significant difference was found between male and female, for the age, the duration of the diabetes and the body mass index (BMI). The type 2 diabetes was predominant in the Akan group ethnic. The diabetics have no education at $45 \%$. They have complications of diabetes at $83 \%$, and $8 \%$ are under insulin therapy. The presumed healthy controls had a mean age of $41.20 \pm 10.25$ years and an average body mass index of $24.72 \pm 4.71$. There was no significant difference between the BMI of the diabetics and that of the controls.

\section{Hyperhomocysteinemia in the type 2 diabetic population}

The prevalence of the hyperhomocysteinemia in our diabetic sample was $36.50 \%$, distributed between $47.95 \%$ in men and $52.05 \%$ in women (Table 2). This hyperhomocysteinemia has a significant relative risk of $2.83 \approx 3$; CI $95 \%$ (by Mittinen method):1.39-11.53, $\left.\mathrm{P}\left(\chi^{2}\right)<0.05\right)$ (Table 3). The $\chi^{2}$ observed was 6.73 ; and the $\chi^{2}(1$; $0.95)$ was 3.84 (Table 3$)$. The observed $\chi^{2}$ is greater than $\chi^{2}(1$; 0.95). The Pearson Chi-square test has indicated a significant positive relationship between the type 2 diabetes and the hyperhomocysteinemia. In this study, the estimated relative risk is considered retrospectively. The hyperhomocysteinemia had enough time to develop in a distant past compared to the date of inclusion of diabetics in this study. The average of hyperhomocysteinemia was $14.84 \pm 3.26 \mu \mathrm{mol} / \mathrm{L}$ (Table 4). The average of hyperhomocysteinemia in men was $14.95 \pm 3.26 \mu \mathrm{mol} / \mathrm{L}$. It was greater than that of the women which was $14.75 \pm 3.07 \mu \mathrm{mol} / \mathrm{L}$; however without 
Table 1. Sociodemographic characteristics of the study population.

\begin{tabular}{|c|c|c|}
\hline Diabetic population (n) & 200 & $\mathbf{P}$ \\
\hline Diabetic men $(\mathrm{n}=78)(\%)$ & 39 & \\
\hline Diabetic women $(\mathrm{n}=122)(\%)$ & 61 & \\
\hline Sex ratio (Men/Women) & 0.6 & \\
\hline Average age (year) & $55 \pm 10.78$ & $<0.05$ \\
\hline Average duration of diabetes (year) & $8.5 \pm 0.70$ & $<0.05$ \\
\hline \multicolumn{3}{|l|}{ Complications of diabetes } \\
\hline With complications $(\%)$ & 83 & \\
\hline Without complications $(\%)$ & 9 & \\
\hline Under insulin therapy $(\%)$ & 8 & \\
\hline Body mass index (BMI) $\left(\mathrm{kg} / \mathrm{m}^{2}\right)$ & $25.63 \pm 4.49$ & $<0.05$ \\
\hline \multicolumn{3}{|l|}{ Distribution of diabetics } \\
\hline Ivorians $(\%)$ & 85.5 & \\
\hline African Foreigners $(\%)$ & 14.5 & \\
\hline Burkinabe $(\%)$ & 7 & \\
\hline Malians (\%) & 2.5 & \\
\hline Guineans $(\%)$ & 1.5 & \\
\hline Ghanians $(\%)$ & 1 & \\
\hline Mauritanians (\%) & 1.5 & \\
\hline Nigerians $(\%)$ & 0.5 & \\
\hline Benineses $(\%)$ & 0.5 & \\
\hline \multicolumn{3}{|l|}{ Ethnic group } \\
\hline Akan $(\%)$ & 50.5 & \\
\hline Gur $(\%)$ & 6.5 & \\
\hline Krou $(\%)$ & 8.5 & \\
\hline Mandé of south (\%) & 4.5 & \\
\hline Mandé of north (\%) & 15 & \\
\hline Other Africans (\%) & 14.5 & \\
\hline \multicolumn{3}{|l|}{ Level of education } \\
\hline Without education $(\%)$ & 45 & \\
\hline Primary $(\%)$ & 26.5 & \\
\hline Secondary $(\%)$ & 27.5 & \\
\hline Supérieur $(\%)$ & 1 & \\
\hline Presumed healthy control population (n) & 31 & $\mathbf{P}$ \\
\hline $\operatorname{Men}(\mathrm{n}=18)(\%)$ & 58.1 & \\
\hline Women $(\mathrm{n}=13)(\%)$ & 41.9 & \\
\hline Sex ratio (Men/Women) & 1.38 & \\
\hline Average age (year) & $41.2 \pm 10.25$ & $>0.05$ \\
\hline Body mass index (BMI) $\left(\mathrm{kg} / \mathrm{m}^{2}\right)$ & $24.72 \pm 4.71$ & $<0.05$ \\
\hline
\end{tabular}

Table 2. Distribution of the hyperhomocysteinemia prevalence in the type 2 diabetic population.

\begin{tabular}{|c|c|c|c|c|c|c|c|}
\hline & & \multicolumn{2}{|c|}{ Hyperhomocysteinemics } & \multicolumn{2}{|c|}{ Normohomocysteinemics } & \multicolumn{2}{|c|}{ Total } \\
\hline & & $\mathbf{n}$ & $\%$ & $\mathbf{n}$ & $\%$ & $\mathbf{n}$ & $\%$ \\
\hline \multirow{4}{*}{$\begin{array}{c}\text { Type } 2 \\
\text { Diabetic Patients }\end{array}$} & Men & 35 & 47.95 & 43 & 33.86 & 78 & 39 \\
\hline & Women & 38 & 52.05 & 84 & 66.14 & 122 & 61 \\
\hline & Total & 73 & 100.00 & 127 & 100.00 & 200 & 100 \\
\hline & Prevalence & & $36.50 \%$ & & $63.50 \%$ & & \\
\hline
\end{tabular}


Table 3. Estimation of the relative risk of hyperhomocysteinemia in the diabetic population.

\begin{tabular}{|c|c|c|c|}
\hline & $\begin{array}{c}\text { Hyperhomocysteinemia } \\
\text { (Exposed) } \\
\mathbf{n}\end{array}$ & $\begin{array}{c}\text { Normohomocysteinemia } \\
\text { (Not Exposed) } \\
\mathbf{n}\end{array}$ & Total \\
\hline Type 2 diabetics $(\mathrm{n}=200)$ & 73 & 127 & 200 \\
\hline Non-diabetic controls $(\mathrm{n}=31)$ & 4 & 27 & 31 \\
\hline Total & $\mathbf{7 7}$ & $\mathbf{1 5 4}$ & $\mathbf{2 3 1}$ \\
\hline
\end{tabular}

Estimated Relative Risk $=2.83 \approx 3(>1)$. That suggests an association between the hyperhomocysteinemia and the type 2 diabetes. $\chi^{2}$ observed : $6.73 ; \chi^{2}(1 ; 0.95): 3.84 ; \chi^{2}$ observed $>\chi^{2}(1 ; 0.95) ; \mathrm{P} \chi^{2}<0.05$

CI 95\% (by Miettinen method): $1.39-11.53$. The observed $\chi^{2}$ is greater than $\chi^{2}(1 ; 0.95)$, suggesting that the hyperhomocysteinemia is significantly higher in diabetic hyperhomocyteinemic patients than in non-diabetic controls. The estimated relative risk is considered retrospectively. The hyperhomocysteinemia had enough time to develop in a distant past compared to the date of inclusion of diabetics in this study.

Table 4. Distribution of the type 2 diabetic hyperhomocysteinemia according to the sex.

\begin{tabular}{|c|c|c|c|c|}
\hline $\mathbf{( N = 7 3 )}$ & Men (M) & Women (W) & M+W & $\mathbf{P}$ \\
\hline $\mathrm{n}$ & 35 & 38 & 73 & 100 \\
\hline$\%$ & 47.95 & 52.05 & & \\
\hline$\overline{\mathrm{x}} \pm \sigma[\min -\mathbf{m a x}](\mu \mathrm{mol} / \mathbf{L})$ & $14.95 \pm 3.50[12-28.76]$ & $14.75 \pm 3.05[12.01-28.26]$ & $14.84 \pm 3.26[12-28.76]$ & $>0.05$ \\
\hline
\end{tabular}

P : Significance; $\bar{z}$ : Average of Homocysteinemia; $\sigma:$ Standard Deviation; min: Minimum; max: Maximum

Table 5. Distribution of the type 2 diabetic hyperhomocysteinemia according to the age class.

\begin{tabular}{|c|c|c|c|c|}
\hline $\mathbf{( N = 7 3 )}$ Age class & $\mathbf{n}$ & $\mathbf{\%}$ & $\overline{\mathbf{z}} \pm \sigma[\mathbf{m i n}-\mathbf{m a x}](\boldsymbol{\mu m o l} / \mathbf{L})$ & $\mathbf{p}$ \\
\hline 20-29 years & 0 & & $00 \pm 00$ & $\mathrm{~ns}$ \\
\hline 30-39 years & 1 & 1.37 & $12.63 \pm 0.00$ & $\mathrm{~ns}$ \\
\hline 40-49 years & 7 & 9.59 & $14.37 \pm 3.01[12.00-19.48]$ & $\mathrm{ns}$ \\
\hline 50-59 years & 36 & 49.31 & $14.64 \pm 2.23[12.15-17.72]$ & $<0.05$ \\
\hline $60-69$ years & 23 & 31.51 & $15.90 \pm 3.47[12.01-28.76]$ & $<0.05$ \\
\hline $70-86$ years & 6 & 8.22 & $16.67 \pm 4.35[12.16-23.45]$ & $\mathrm{ns}$ \\
\hline
\end{tabular}

P: Significance; $\bar{x}$ : Average of Homocysteinemia; $\sigma:$ Standard Deviation; min: Minimum; max: Maximum; ns: Not Significant

any signifycant difference (Table 4). This hyperhomocysteinemia evolved with age (Table 5).

According to the classification of the hyperhomocysteinemias of Faeh et al., [12], only one type of hyperhomocysteinemia (12-30 $\mu \mathrm{mol} / \mathrm{L})$ emerged from our study. This was a moderate hyperhomocysteinemia. No diabetic patient did either an intermediate hyperhomocysteinemia (31-100 $\mu \mathrm{mol} / \mathrm{L})$ or a severe hyperhomocysteinemia $(\geq 100 \mu \mathrm{mol} / \mathrm{L})$. A significant difference in the hyperhomocysteinemia was found between the Akan group ethnic and those of the Krou, the Gur, and the "northern Mandé" ethnic groups (Table 6). Also, a significant difference in hyperhomocysteinemia existed between the "Other Africans" ethnic group and the Gur ethnic group (Table 6).

\section{Study of the biological variables in the type 2 diabetic hyper- homocysteinemia}

Regarding the biological variables (Table 7), there was a significant difference between the subpopulation of diabetics with hyperho- mocysteinemia and the control group: for the homocysteinemia, the glycemia and the lipid parameters (total cholesterol, triglycerides, LDL cholesterol, HDL cholesterol and atherogenicity index). In these diabetic patients, the values of the total cholesterol, the triglycerides, the LDL-cholesterol and the HDL-cholesterol were within the normal reference ranges (Table 7).

\section{Discussion}

The hyperhomocysteinemia is an independent vascular risk factor [5]. Its effect is particularly more deleterious in diabetics than in non-diabetics $[2,7]$. In this context, an exploration of the importance of the hyperhomocysteinemia in the type 2 diabetics in Côte d'Ivoire was necessary in view of a nutritional and a clinical management. The present study has revealed a prevalence of diabetic hyperhomocysteinemia of $36.50 \%$. The hyperhomo-cysteinemia affected men and women in almost equal proportions: $47.95 \%$ in men and $52.05 \%$ in women. The relative risk of the diabetic hyperhomocysteinemia was approximately $3(\mathrm{RR}=2.8$, CI $95 \%$ : $\left.1.39-11.53, \mathrm{P}\left(\chi^{2}\right)<0.05\right)$. It is greater than 1 . That suggests an as- 
Table 6. Distribution of the hyperhomocysteinemia according to the ethnic group.

\begin{tabular}{|c|c|c|c|c|}
\hline $\mathbf{( N = 7 3 )}$ Enthnic group & $\mathbf{n}$ & $\mathbf{\%}$ & $\overline{\mathbf{x}} \pm \sigma[\mathbf{m i n}-\mathbf{m a x}](\boldsymbol{\mu m o l} / \mathbf{L})$ & $\mathbf{p}$ \\
\hline Akan & 42 & 57.53 & $15.95 \pm 5.70[12.00-28.76]$ & $<0.05$ \\
\hline Other Africans & 12 & 16.44 & $13.63 \pm 3.73[12.07-16.79]$ & $<0.05$ \\
\hline Mandé of north & 8 & 10.96 & $15.69 \pm 3.11[13.22-17.32]$ & $<0.05$ \\
\hline Krou & 5 & 6.85 & $15.32 \pm 4.59[12.54-23.45]$ & $<0.05$ \\
\hline Gur & 3 & 4.11 & $15.04 \pm 1.25[13.36-17.29]$ & $<0.05$ \\
\hline Mandé of south & 3 & 4.11 & $13.42 \pm 1.19[12.15-14.57]$ & $<0.05$ \\
\hline
\end{tabular}

P: Significance; $\overline{\mathrm{z}}$ : Average of Homocysteinemia; $\sigma:$ Standard Deviation; min: Minimum; max: Maximum.

Table 7. Mean biological values of diabetics and controls.

\begin{tabular}{|c|c|c|c|c|c|c|}
\hline & \multicolumn{2}{|c|}{$\begin{array}{c}\text { Hyperhomocysteinemic } \\
\text { diabetics (N=73) }\end{array}$} & \multicolumn{2}{c|}{ Control group (N=31) } & \multirow{2}{*}{$\begin{array}{c}\text { Reference } \\
\text { Values }\end{array}$} & \multirow{2}{*}{$\mathbf{P}$} \\
\cline { 2 - 5 } & $\bar{\Sigma} \pm \sigma$ & {$[$ min-max] } & $\bar{\Sigma} \pm \sigma$ & {$[$ min-max] } & & \\
\hline Glyc & $1.53 \pm 0.81$ & {$[0.78-4.63]$} & $0.85 \pm 0.09$ & {$[0.71-1.04]$} & $0.7-1.10 \mathrm{~g} / \mathrm{L}$ & $<0.05$ \\
\hline CT & $2.07 \pm 0.60$ & {$[0.86-4.59]$} & $1.94 \pm 0.35$ & {$[1.39-2.62]$} & $1.06-2.50 \mathrm{~g} / \mathrm{L}$ & $<0.05$ \\
\hline HDL & $0.43 \pm 0.11$ & {$[0.12-1.35]$} & $0.66 \pm 0.16$ & {$[0.32-0.91]$} & $0.26-0.70 \mathrm{~g} / \mathrm{L}$ & $<0.05$ \\
\hline LDL & $1.42 \pm 0.57$ & {$[0.37-2.55]$} & $1.11 \pm 0.34$ & {$[0.47-1.69]$} & $0.55-1.30 \mathrm{~g} / \mathrm{L}$ & $<0.05$ \\
\hline TG & $1.04 \pm 0.33$ & {$[0.39-1.77]$} & $0.77 \pm 0.27$ & {$[0.36-1.47]$} & $0.30-1.20 \mathrm{~g} / \mathrm{L}$ & $<0.05$ \\
\hline HCY & $14.84 \pm 3.26$ & {$[12.00-28.78]$} & $10.74 \pm 2.38$ & {$[6.07-15.67]$} & $<12 \mu \mathrm{mol} / \mathrm{L}$ & $<0.05$ \\
\hline IA & $5.15 \pm 2.44$ & {$[1.58-16.55]$} & $3.02 \pm 0.78$ & {$[1.75-4.59]$} & $<3.30$ & $<0.05$ \\
\hline
\end{tabular}

P: Significance; $\overline{\mathrm{z}}$ : average; $\sigma$ : Standard Deviation; min: Minimum; max: Maximum; HCY: Homocysteinemia; Glyc: Glycemia; CT: Total Cholesterol; TG: Triglycerides; LDL: Low Density Lipoprotein Cholesterol; HDL: High Density Lipoprotein Cholesterol; IA: Atherogenicity Index.

The control group is composed of non diabetic subjects presumed healthy.

sociation between the hyperhomocysteinemia and the type 2 diabetes. The observed $\chi^{2}$ is greater than $\chi^{2}(1 ; 0.95)$, suggesting that the hyperhomocysteinemia risk is significantly higher in diabetic hyperhomocyteinemic patients than in non-diabetic controls. The hyperhomocysteinemia is a reality in Côte d'Ivoire. The hyperhomocysteinemia must be taken into account in the treatment of the diabetics in Côte d'Ivoire. Our study is corroborated by that of Cissé et al. [8] realized in the type 2 diabetics in Senegal, in which the relative risk of hyperhomocysteinemia was 2.39 , for a prevalence of $42.5 \%$.

In this study, the values of the diabetic hyperhomocysteinemia were higher in men $(14.95 \pm 3.50 \mu \mathrm{mol} / \mathrm{L})$ than in women $(14.75$ $\pm 3.05 \mu \mathrm{mol} / \mathrm{L})$, with no significant difference. Houzé et al., [13] did not also found a significant difference of the hyperhomocysteinemia according to the sex, although it was higher in men than in women. That was in agreement with our results. Contradictorily, Cissé et al., [8] had found that the hyperhomocysteinemia was higher in the diabetics women than in men, however without significant difference. The difference in the homocysteinemia values between the two sexes could be explained by several factors: the hormonal state of the woman, the muscle mass of the man and the differences related to the lifestyle [8]. The homocysteinemia values in women are similar to those of men after menopause [14]. At the menopause, the protective effect of the estrogens against the hyperhomocysteinemia ceases, due to their fall [15]. The age is a hyperhomocysteinemia risk factor [15]. Our study has revealed that the diabetic hyperhomocysteinemia evolves with age. It was not significant at ages less than 50 years, significant between 50 and 70 years, and not significant at ages above 70 years. Glowinska et al., [16] haven't found a significant difference in the gradual increase of the hyperhomocysteinemia during the early stages of the macrovascular complications of the diabetes. This could explain the no significant increase in hyperhomocysteinemia at ages less than 50 years. We also found that the period of the significant increase of the hyperhomocysteinemia (between 50 and 70 years) corresponded to the period of the manifestation of the type 2 diabetes $(55 \pm 10.78$ years). That suggests that between the ages of 50 and 70, there are synergistic metabolic interactions between the type 2 diabetes and the hyperhomocysteinemia. At the ages superior to 70 years, no significant increase of the hyperhomocysteinemia was observed, probably because of the small number of diabetics $(n=6)$ repre-senting this age group. The study of Cissé et al., [8] corroborates our findings for the increased of the hyperhomocysteinemia with age. The increase of the hyperhomocysteinemia with age could be explained in part by the physiological decline of the renal function associated with aging [15]. The homocysteine increases linearly between 60 and 65 years of age, and then is accentuated rapidly beyond 65 years, averaging $10 \%$ or $1 \mu \mathrm{mol} / \mathrm{L}$ per year [15].

Our study has showed a significant difference in the hyperhomocysteinemia between that of the Akan group ethnic group and that of the Krou, the Gur and the northern Mandé ethnic groups. 
Also, there was a significant difference in the hyperhomocysteinemia between that of the "Other Africans" ethnic group and that of the Gur ethnic group. That suggests the implication of nutritional, genetic and lifestyle differences in the manifestation of the type 2 diabetic hyperhomocysteinemia in Côte d'Ivoire. The Ivorian studies devoted to the genetic causes of the hyperhomocysteinemia are scares. The Ivorian study of Tiahou et al., [9] was to our knowledge the only study that has suspected the effect of a possible heterozygous genetic mutation of the cystathionine $\beta$-synthase ("844 ins68" mutation) in healthy subjects. And that, because of the homocysteine/folate ratio $\geq 4.4$ indicating the existence of heterozygous mutations of the cystathionine $\beta$-synthase (CBS) in non-diabetic Ivoirians. The heterozygous mutations "844ins68" of the CBS may lead to a moderate or an intermediate hyperhomocysteinemia [9]. A high prevalence of the heterozygous mutation "844ins 68 of the CBS" of $37.7 \%$ was observed in black populations of Africa [17]. Pepe et al., [18] had even reported $66.66 \%$ frequency of the CBS heterozygous mutation 844ins 86 in sub-Saharan Africans. Further studies are needed to explain the genetic difference of the diabetic hyperhomocysteinemia in different Ivorian ethnic groups.

The mean of the diabetic hyperhomocysteinemia in our study was $14.84 \pm 3.26 \mu \mathrm{mol} / \mathrm{L}$. Cissé et al., [8] have also found an average of diabetic hyperhomocysteinemia $(15.42 \pm 4.06 \mu \mathrm{mol} / \mathrm{L})$ very close to that we had obtained.

In the study of Eun-Hee et al., [19], the type 2 diabetics who developed the microalbuminuria (diabetic nephropathy) had a significantly higher homocysteinemia $(11.80 \pm 3.70 \mu \mathrm{mol} / \mathrm{L})$ than those who did not develop it $(10.30 \pm 3.10 \mu \mathrm{mol} / \mathrm{L})$. The risk of the diabetic nephropathy was present at a homocysteinemia well below $15 \mu \mathrm{mol} / \mathrm{L}$ [19]. According to Eun-Hee et al., (2010), a homocysteinemia of $11.80 \pm 3.70 \mu \mathrm{mol} / \mathrm{L}$ was sufficient to develop the diabetic nephropathy. Thus, our diabetic patients, with a homocysteinemia of $14.84 \pm 3.26 \mu \mathrm{mol} / \mathrm{L}$, also have all the possibilities to develop diabetic nephropathy.

According to Rigaud [20], the relative risk of hyperhomocysteinemia for the development of the cerebrovascular lesions is 2.3 , and 1.8 for coronary heart disease. Thus, our diabetic patients, with a relative risk of hyperhomocysteinemia of about $3(\mathrm{RR}=2.83, \mathrm{P}$ $\left.\left(\chi^{2}\right)<0.05\right)$, also have all the chance to develop the cerebrovascular lesions and the coronary diseases.

In a cohort of the type 2 diabetics, $70 \%$ of patients with hyperhomocysteinemia had a macroangiopathy compared to $42 \%$ of the normohomocysteinemic patients [14]. In the study of Vangelder et al., [6] realized in 185 diabetic type 2 patients, the homocysteinemia was $13.1 \pm 2.3 \mu \mathrm{mol} / \mathrm{L}$ in patients without cardiovascular complications and $15.4 \pm 3.5 \mu \mathrm{mol} / \mathrm{L}$ in patients with cardiovascular complications $(\mathrm{p}<0.001)$. As a result, the authors concluded that hyperhomocysteinemia was a risk factor for cardiovascular complications in patients with type 2 diabetes [6]. Therefore, with a relative risk of hyperhomocysteinemia of about $3(\mathrm{RR}=2.83$, $\left.\mathrm{P}\left(\chi^{2}\right)<0.05\right)$ and a mean of homocysteinemia of $14.84 \pm 3.26$ $\mu \mathrm{mol} / \mathrm{L}$, our diabetics have all the possibilities to develop the micro and macrovascular complications related to diabetic hyperhomocysteinemia, according to the studies precited.

The hyperhomocysteinemia in our study corresponds to a mod- erate hyperhomocysteinemia $(12-30 \mu \mathrm{mol} / \mathrm{L})$ according to the classification of Faeh et al., [12]. Given the particularly deleterious character of the hyperhomocysteinemia in diabetics compared with non-diabetic patients, the pathological threshold in this study was set at $12 \mu \mathrm{mol} / \mathrm{L}$, in agreement with the Homocysteine Group of France in 2001. In fact, the cardiovascular risk of the hyperhomocysteinemia is already present between 10 and $15 \mu \mathrm{mol} / \mathrm{L}$ [21], well below the arbitrary pathological threshold commonly set at $15 \mu \mathrm{mol} / \mathrm{L}$ in healthy subjects. No diabetics in our study had an intermediate hyperhomocysteinemia (31-100 $\mu \mathrm{mol} / \mathrm{L})$. In addition, no patients had severe homocysteinemia $(\geq 100 \mu \mathrm{mol} / \mathrm{L})[5,14]$, leading to a suspicion of a genetic cause of hyperhomocysteinemia $[5,22]$.

The moderate hyperhomocysteinemias are generally due to vitamin B deficiencies. According to Demuth [5], the moderate hyperhomocysteinemia can have a nutritional, pathological or a therapeutic origin. In our study, the causes of the moderate hyperhomocysteinemia could be majoritarely nutritional. $45 \%$ of our diabetics are without education. The ignorance and the poverty helping, they do not escape the vitamin B deficiencies leading to the hyperhomocysteinemia. The diabetes is also a cause of the hyperhomocysteinemia [22]. The metformin, a drug administered to the diabetics, contributes to the hyperhomocysteinemia [14]. We have observed that the hyperhomocysteinemia evolved gradually with age. It is quite possible that the destructured dietary habits have contributed to that moderate hyperhomocysteinemia. All these specific causes mentioned above, without being exhausttive, could explain the emergence of the moderate hyperhomocysteinemias observed in our type 2 diabetic subjects.

The hyperhomocysteinemia remains a major cardiovascular risk in the type 2 diabetic patients. Our study has showed a significant glycemia in the hyperhomocysteinemic diabetics compared to control group, suggesting possible synergistic interactions between the diabetes and the hyperhomocysteinemia. The studies linking the insulin resistance to plasma homocysteine levels are discordant [23]. Although the physiological mechanisms linking the insulin resistance to the hyperhomocysteinemia are not elucidated, it was observed that plasma homocysteine concentrations were frequently increased with the insulin resistance [23], suggesting a link between the hyperhomocysteinemia and the insulin resistance. The diabetes via its free radicals potentiates the deleterious effects of the hyperhomocysteinemia on the vascular endothelium [24]. The diabetes and the hyperhomocysteinemia are associated with early vascular lesions with rapid progression [24]. The hyperinsulinism, on the other hand, participates to the hyperhomocysteinemia by interfering with the activity of the homocysteine metabolism enzymes. Indeed, the hyperinsulinism or an excessive insulin therapy promotes the inhibition of the enzymes in the transsulfuration pathway, and de facto leads to the hyperhomocysteinemia [25]. The study of Fonseca et al., [26] has showed a significantly negative correlation between the hyperinsulinism and the activity of the cystathionine $\beta$-synthase. That suggests that in patients with type 2 diabetes, the hyperinsulinism contributes to the hyperhomocysteinemia by inhibiting the enzymatic activity of the cystathionine $\beta$-synthase. The diabetes could promote the hyperhomocysteinemia, since the hyperinsulinemia prevents the body from reducing the hyperhomocysteinemia and maintain a normal homocysteine [2]. 
In this study, the atherogenic (total cholesterol, LDL-cholesterol, triglycerides) and the antiatherogenic (HDL) lipid parameters are normalized in our diabetic patients. The atherogenicity index of cholesterol is also within the limits of the normality. This could be explained by the fact that they are mostly under anti-lipid and dietetic treatment. They are regularly monitored at the Abidjan Antidiabetic Center (CADA) and at the Nutrition Center of the National Institute of Public Health in Abidjan. The study of Cissé et al., (2015) [8] in which these lipid parameters are insignificant, corroborates our results.

\section{Conclusion}

The hyperhomocysteinemia is a reality in the type 2 diabetics in Côte d'Ivoire. It should be the object of sensibilization and reinforcement of the dietary and therapeutic measures, in order to minimize the risk of the cardiovascular diseases incurred by the type 2 diabetics.

\section{References}

[1]. Peyrin-Biroulet L. Homocysteinemia, a new marker of severity in IBD ?. Hepato-Gastroenterology. 2007 Mar 1; 14(2):149-56.

[2]. Grunitzky K, Balogou K, Bark-kombate R, Kombate D, Amouzou K. Homocysteinemia and ischemic strokes at the CHU Campus of Lomé. [Afr J Neurol Sci. 2008;27(2):3-7.

[3]. Keel M, Berthe MC, Sauger F, Lavoinne A. Plasma homocysteine assay on Immulite 2000 DPC: comparison with the IMX Abbott assay. Ann Clin Biol. 2003 Nov 1;61(6):699-704.

[4]. Demets JP. A study by researchers at Harvard University has shown that too much homocysteine in the blood has a risk factor that can lead to cardiovascular disorders. But what is homocysteine? [Internet]. 2002 [cited 2017 Apr 17].

[5]. Demuth K. Homocysteine and cardiovascular prevention in the elderly. Ann Clin Biol. 2001 Jul 24;59(4):465-8.

[6]. Vangelder E, Delecourt F, Cardozo MB, Dhondt JL, Forzy G. Hyperhomocysteinemia and Type 2 Diabetes. Ann Clin Biol. 2006 Sep 1;64(5):485-489.

[7]. Guldener CV, Stehouwer CD. Homocysteine and vascular complications of diabetes. Diabetes Voice. 2003;48:31-33.

[8]. Cisse F. Hyperhomocysteinemia and type 2 diabetes. CAMES review: J Health Sci. 2015 Oct 27;3(1).

[9]. Tiahou G, Dupuy AM, Jaussent I, Sees D, Cristol JP, Badiou S. Determinants of homocysteine levels in Ivorian rural population. Int J Vitam Nutr Res. 2009 Sep 1;79(56):319-27.

[10]. Djohan FY. Interest in the Assay of Homocysteine, Vitamin B12 and Folic acid in cardiovascular diseases in cote D'ivoire. Cames Review: J Health Sci. 2013 Apr 11;1(2).
[11]. Yapo AE, Assayi M, Comoe L, Lonsdorfer A, Monnet D, Diaine C. The reference values of 21 biochemical blood constituents of adult Ivorian presumed healthy. Afr Med Pub. 1990 (110):49-57.

[12]. Faeh D1, Chiolero A, Paccaud F. Homocysteine as a risk factor for cardiovascular disease: should we (still) worry about?. Swiss Med Wkly. 2006 Dec 2;136(47-48):745-56. PubMed PMID: 17225194.

[13]. Houze P, Dussaucy M, Courties Y, Bousquet B. Evaluation of the Bio-Rad technique for the determination of total plasma homocysteine by high performance liquid chromatography. Ann Clin Biol. 1999 Oct 12;57(5):611-6.

[14]. Buysschaert M, Hermans MP. How I treat and manage hyperhomocysteinemia. Flammarion Med Sci. 2003; (9):229-37.

[15]. Stanger O, Hermann W, Pietrzik K, Fowler B, Geisel J, Weger M. Consensus article of DACH-Liga-Homocysteine on the rational clinical use of homocysteine, folic acid and B vitamins in cardiovascular and thrombotic diseases. Guidelines and recommendations [Internet]. 2012 [cited 2017 Mar 20].

[16]. Glowinska B, Urban M, Koput A, Galar M. New atherosclerosis risk factors in obese, hypertensive and diabetic children and adolescents. Atherosclerosis. 2003 Apr 1;167(2):275-86. PubMed PMID: 12818410.

[17]. Franco RF, Elion J, Lavinha J, Krishnamoorthy R, Tavella MH, Zago MA. Heterogeneous ethnic distribution of the 844 ins 68 in the cystathionine $\beta$-synthase gene. Hum Hered. 1998 Nov-Dec;48(6):338-42. PubMed PMID: 9813456.

[18]. Pepe G, Vanegas OC, Giusti B, Brunelli T, Marcucci R, Attanasio M, et al. Heterogeneity in world distribution of the thermolabile C677T mutation in 5, 10-methylenetetrahydrofolate reductase. Am J Hum Genet. 1998 Sep;63(3):917-20. PubMed PMID: 9718345.

[19]. Cho EH, Kim EH, Kim WG, Jeong EH, Koh EH, Lee WJ, et al. Homocysteine as a risk factor for development of microalbuminuria in type 2 diabetes. Korean Diabetes J. 2010 Jun;34(3):200-6. PubMed PMID: 20617081.

[20]. Rigaud D. Hyperhomocysteinemia and cardiovascular diseases due to atherosclerosis. The cardiologist's letter. 1999;309: 26-30.

[21]. Ueland PM, Refsum H, Beresford SA, Vollset SE. The controversy over homocysteine and cardiovascular risk. Am J Clin Nutr. 2000 Aug 1;72(2):32432.

[22]. Zittoun J. Homocysteine and Vascular Pathology. Hematol. 1998;4:7-16.

[23]. Tessari P, Kiwanuka E, Coracina A, Zaramella M, Vettore M, et al. Insulin in methionine and homocysteine kinetics in healthy humans: plasma vs. intracellular models. Am J Physiol Endocrinol Metab. 2005 Jun;288(6):E1270-6.

[24]. Benmerabet S, Fredenrich A, Robillon JF, Canivet B, Candito M, Obberghen EV. Should we measure homocysteine in diabetic patients? Diabetes Metab. 2002;28: 510-515.

[25]. Abu-Lebdeh HS, Barazzoni R, Meek SE, Bigelow ML, Persson XM, Nair KS. Effects of insulin deprivation and treatment on homocysteine metabolism in people with type 1 diabetes. J Clin Endocrinol Metab. 2006 Sep;91(9):3344-8. PubMed PMID: 16772348.

[26]. Fonseca V, Guba SC, Fink LM. Hyperhomocysteinemia and the endocrine system: implications for atherosclerosis and thrombosis. Endocr Rev. 1999 Oct;20(5):738-59. PubMed PMID: 10529901.

[27]. Friedewald WT, Levy RI, Fredrickson DS. Estimation of the concentration of low-density lipoprotein cholesterol in plasma, without use of the preparative ultracentrifuge. Clin Chem. 1972 Jun;18(6):499-502. PubMed PMID: 4337382. 